Research Article

\title{
Experimental Study of Reinforcing Broken Gangues by Colloid Cement Slurry
}

\author{
Xin Lyu $\mathbb{D}^{1},{ }^{1}$ Ke Yang $\mathbb{D}^{1},{ }^{1}$ Qiang Fu $\mathbb{D}^{1},{ }^{1}$ Zhen Wei $\mathbb{D}^{1},{ }^{1}$ and Shuai Liu $\mathbb{D}^{1,2}$ \\ ${ }^{1}$ State Key Laboratory of Mining Response and Disaster Prevention and Control in Deep Coal Mines, \\ Anhui University of Science and Technology, Huainan 232001, China \\ ${ }^{2}$ School of Resources and Civil Engineering, Northeastern University, Shenyang 110819, China
}

Correspondence should be addressed to Ke Yang; keyang2003@163.com

Received 31 January 2021; Revised 31 March 2021; Accepted 17 April 2021; Published 23 April 2021

Academic Editor: Guangyao Si

Copyright (c) 2021 Xin Lyu et al. This is an open access article distributed under the Creative Commons Attribution License, which permits unrestricted use, distribution, and reproduction in any medium, provided the original work is properly cited.

\begin{abstract}
Studies on jet grouting materials mainly focus on the aggregates in cement or the environment where they are maintained and rarely deal with the cohesiveness, reinforcement load-bearing characteristics, and surface spalling. In this study, cement slurries with different colloid contents were prepared to explore the characteristics and reinforcement effect of broken gangues. These were then subjected to mechanical testing to measure the strength and axial strain performance, and the failure modes and failure patterns were discussed. The results indicated that the colloid component has a significant strengthening effect on the early strength of the samples. As the age increased, the sample axial strain and elastic modulus of the colloid cement paste increased as the colloid component provides viscoelasticity when it resists deformation. The sample strength of cement paste decreases after the addition of broken gangue while the strength of class $E$ samples increases significantly during each age. The cement paste sample showed penetrating splitting failure, the colloidal component effectively controlled the peeling of sample surface, and the failure mode after adding gangue was relatively complicated. The instability modes of the samples are divided into dispersed load-bearing instability and cumulative load-bearing instability, and the content of colloid components affects the failure mode of the samples. A colloid component proportion of $23.33 \%$ is the optimal choice, which has an obvious reinforcement effect on the broken gangue.
\end{abstract}

\section{Introduction}

In mining and tunnel engineering, stress redistribution often occurs due to change in the original in-situ stress state caused by excavation, formation of collapse zones, fissure zones, and bending subsidence zones, causing the surrounding rock of the roadway to break and become suspended from the roof $[1,2]$. This makes it impossible to form effective support structures and may easily cause safety accidents such as roof collapse. Therefore, grouting and shotcrete reinforcement technology are often applied to improve the crushing condition of surrounding rocks and avoid safety hazards caused by the fall of broken gangues. However, since the cement slurry used underground has a long setting time, low early strength, and insufficient cohesiveness with broken rock, a long curing time is always required after grouting [3]. Hence, though new cement slurries are being studied across the world, investigations on roadway-related applications are still limited to floor heave treatment and roadway repair. Studies on the spray grouting of broken rock are still in the nascent stages.

Some researchers have prospectively reviewed existing materials and their applications in terms of the bearing capacity of cement slurry [4]. Subsequently, the water-cement ratio of cement slurry, curing environment $[5,6]$, material ratio, particle size, and so on were discussed [7-10]. In addition, the influence on the gel time, setting time, compressive strength, and corrosivity of cement slurry were explored by adding sodium silicate, ammonium dihydrogen phosphate, slag $[11,12]$, fly ash [13-15], etc. to it.

Studies on new materials $[16,17]$ are also underway. Limestone composite activator [18], nickel powder 
composite cement [19], and high-strength water reducer cement $[20,21]$ are prepared to meet the challenges that complex mine environments present to cement slurry [22-24]. Moreover, the influences of SAP on hydration, selfshrinkage, mechanical properties, and microstructure of cement slurry were studied [25]. The resistivity of cement material was tested by the direct current four-terminal electrode method, and the influence of the water content of carbon fiber cement material [26] on its resistivity was studied [27]. A simulation test device was designed and the scanning electron microscope test method [28, 29] was adopted to prove that grouting can not only improve the physical and mechanical properties of rocks, but also cause chemical changes in rock components and generate petrolike minerals in the interface region, thus improving the cementation strength of the rock-slurry interface [30-33]. As observed, the above researches mainly considered the ratio of a selected aggregate of materials, which are mostly limited to the testing of the bearing capacity of cement slurry and do not significantly consider the cohesiveness and the actual load-bearing characteristics after reinforcement and surface spalling.

In this study, the reinforcement effect of colloid cement slurry is mainly studied. A rigid testing machine is applied to conduct uniaxial compressive strength on 48 cement paste samples falling in 6 categories, and the compressive strength and axial strain characteristics of different colloid cement paste samples and reinforcing cement paste samples under single-axial compression are studied. The hardening process of cement paste samples with increasing age was analyzed, and the compressive strength and axial strain increase of the reinforcing cement paste samples were determined; in addition, the failure modes of the colloid cement paste samples and reinforcing cement paste samples were discussed to determine the basic failure mode. The results can provide a reference for the selection of injection grouting materials for broken rock layers in roadways.

\section{Single-Axial Compression Test of Colloid Cement Paste}

2.1. Sample Preparation. Colloid cement paste samples were prepared using C32.5R Portland cement and 801 adhesive for construction (Figure 1). In order to accurately compare the strength of different colloid cement paste samples, no aggregate is added. An electronic scale with an accuracy of $10^{-4} \mathrm{~kg}$ is applied to weigh the cement and liquid (water and 801 adhesive for construction) with a mass ratio of $2: 1$. A triple steel assembly cylindrical mold with a specification of $L 100 \mathrm{~mm} \times \Phi 50 \mathrm{~mm}$ is adopted as the sample filling mold to fill the colloid cement paste sample (Figure 2), and a round ram with a diameter of $\Phi 10 \mathrm{~mm}$ and length of $L 350 \mathrm{~mm}$ is applied for tamping during the filling process.

The colloid cement paste samples were demolded after standing for $24 \mathrm{~h}$ under ambient conditions and then moved to the room for water spray curing. The upper and lower cylindrical sections were artificially polished with fine sand to ensure that the roughness did not exceed $0.05 \mathrm{~mm}$ and the nonperpendicularity of each adjacent surface did not exceed $\pm 0.5^{\circ}$.

According to the quantity of 801 adhesive mixed in the process of preparing the colloid cement paste, the samples are divided into three types, namely, class A, class B, and class C. Among them, class A adopts the ratio of $20: 10: 0$ of cement: water: glue, class $B$ adopts the ratio of $20: 3: 7$, and class $C$ adopts the ratio of 20:0:10. According to the designed proportion, 12 pieces of colloid cement paste samples of each type were prepared, and each type was divided into four groups with three samples in each group according to the test age (Figure 3 ).

Due to the phenomenon of water evolution in the hardening process of colloid cement paste samples, two samples with little difference in integrity were selected for each group (sample no: A1-1, A1-1, A2-1, A2-2.....) to conduct uniaxial compressive strength in the early stage of colloid cement paste formation in order to ensure the homogeneity of the tests.

2.2. Single-Axial Compression of Colloid Cement Paste Samples. According to the requirements, the samples were cured to $7 \mathrm{~d}, 14 \mathrm{~d}, 21 \mathrm{~d}$, and $28 \mathrm{~d}$, and the colloid cement paste samples were dried for more than $2 \mathrm{~h}$ before the test to ensure same water content among the samples so that it does not impact the test results.

Use the RMT-150B rock mechanics testing machine (Figure 4) to perform uniaxial compressive strength on the specimen. The following are the steps in the test.

(1) Place the sample on the pressing plate under the rigid testing machine, align the center of the sample with the center of the lower pressing plate of the testing machine, install the dial indicator, and connect the computer terminal system for debugging.

(2) Raise the lower pressing plate of the testing machine so that the upper pressing plate on the top of the machine just touches the cement paste sample. Meanwhile, keep the axis of the cement paste sample coincident with the loading center line of the testing machine to avoid eccentric force, which will affect the test results.

(3) Set the loading rate of $0.03 \mathrm{~mm} / \mathrm{s}$ to load the axial stress to the final failure of the sample.

(4) Recording and saving the data of the whole test process for analysis and processing.

2.3. Characteristics of Colloid Cement Paste in Single-Axial Compression Tests. Uniaxial compressive strength stressstrain curve of colloid cement paste sample is shown in Figure 5, and the data of single-axial compression test of the samples are shown in Table 1.

As shown in Figure 5, the stress-strain curves of cement paste sample with different colloid ratios are quite different at the ages of $7 \mathrm{~d}$ and $21 \mathrm{~d}$, while the difference between the colloid cement paste samples decreases after reaching the standard curing time at the age of $28 \mathrm{~d}$, indicating that 


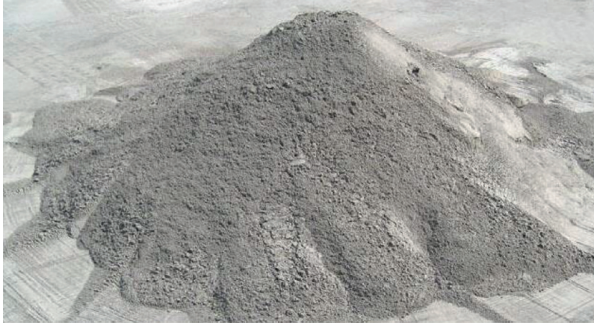

(a)

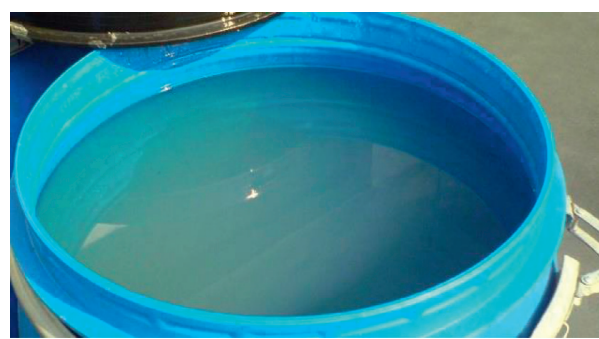

(b)

Figure 1: Materials. (a) Portland cement. (b) 801 adhesive.

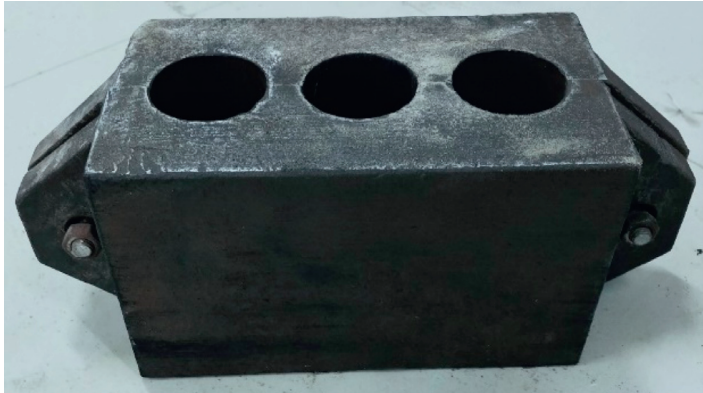

(a)

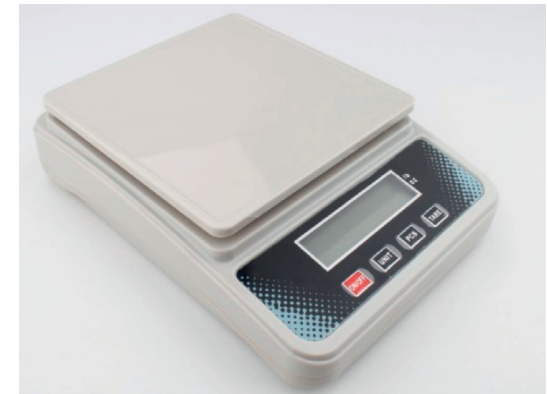

(b)

Figure 2: Tools. (a) Sample filling mold. (b) An electronic scale.
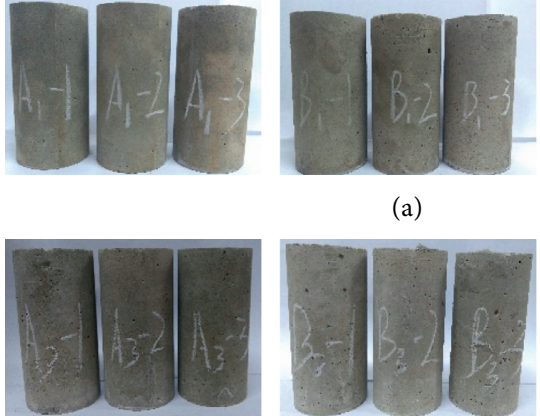

(a)

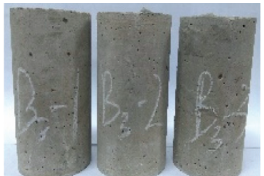

(c)
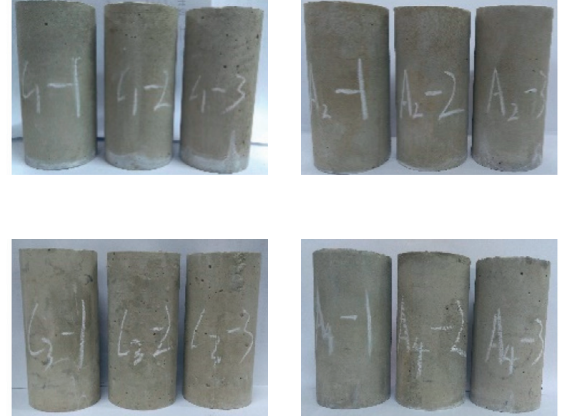

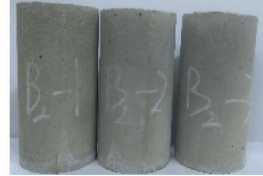

(b)

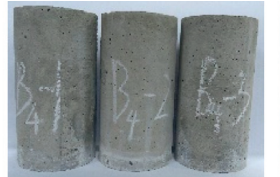

(d)

Figure 3: Colloid cement paste sample. (a) $7 \mathrm{~d}$ age sample. (b) $14 \mathrm{~d}$ age sample. (c) $21 \mathrm{~d}$ age sample. (d) $28 \mathrm{~d}$ age sample.

compressive strength of the samples during the curing period is affected by the hydration and adhesive effect of colloid component, resulting in different strength performance. With the increase of curing time, the stress-strain curves of the specimens show obvious differences. When the curing time is short, the stress-strain curves of the specimens decrease slowly, while when the curing time is long, the stress-strain curves of the specimens decrease suddenly after reaching the peak. The results show that the hydration reaction in the curing process will make the specimen plasticity enhanced.

2.3.1. Relationship between Colloid Cement Paste Age and Compressive Strength. The mean value of the compressive strength of the samples with different ages was adopted to draw the curve (Figure 6). As observed, the compressive strength of the three types of cement paste samples increases with age, and the colloid cement paste samples still follow the law of gradual hardening; however, the increasing trend is also different due to the different contents of the colloid components.

The early strength of colloid cement paste sample of class $\mathrm{B}$ and $\mathrm{C}$ at the age of 7 days is greater than that of class $\mathrm{A}$, with an increase of $15.60 \%$ and $86.92 \%$, respectively, indicating that the early strength of colloid cement paste samples was mainly due to the adhesive effect of colloid component, and the hydration was secondary. As the age increases, the first stage of hydration continues, and, this time, hydration takes the leading role. The hydration of tricalcium silicate at 


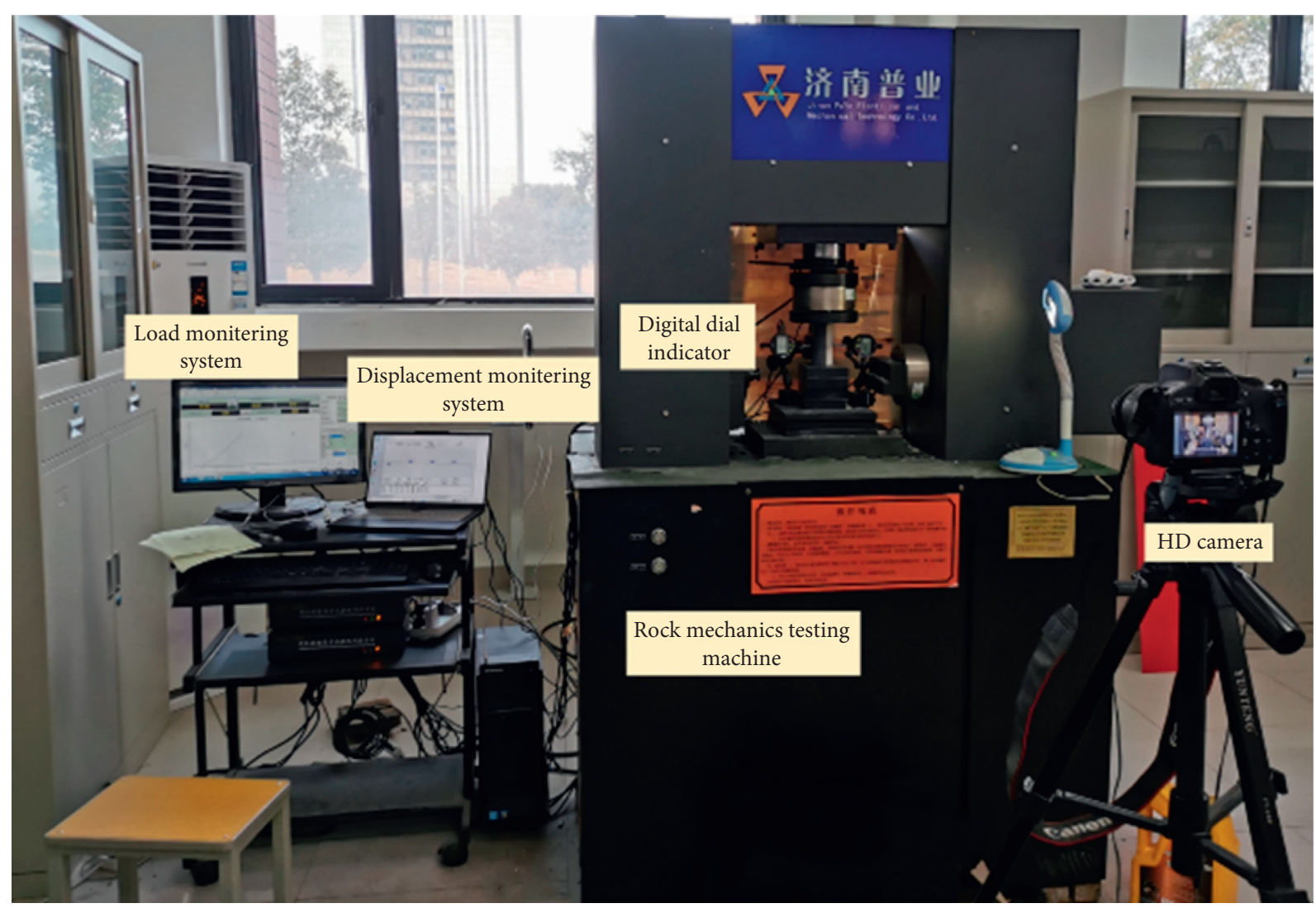

FIgURE 4: Rock mechanics testing machine.
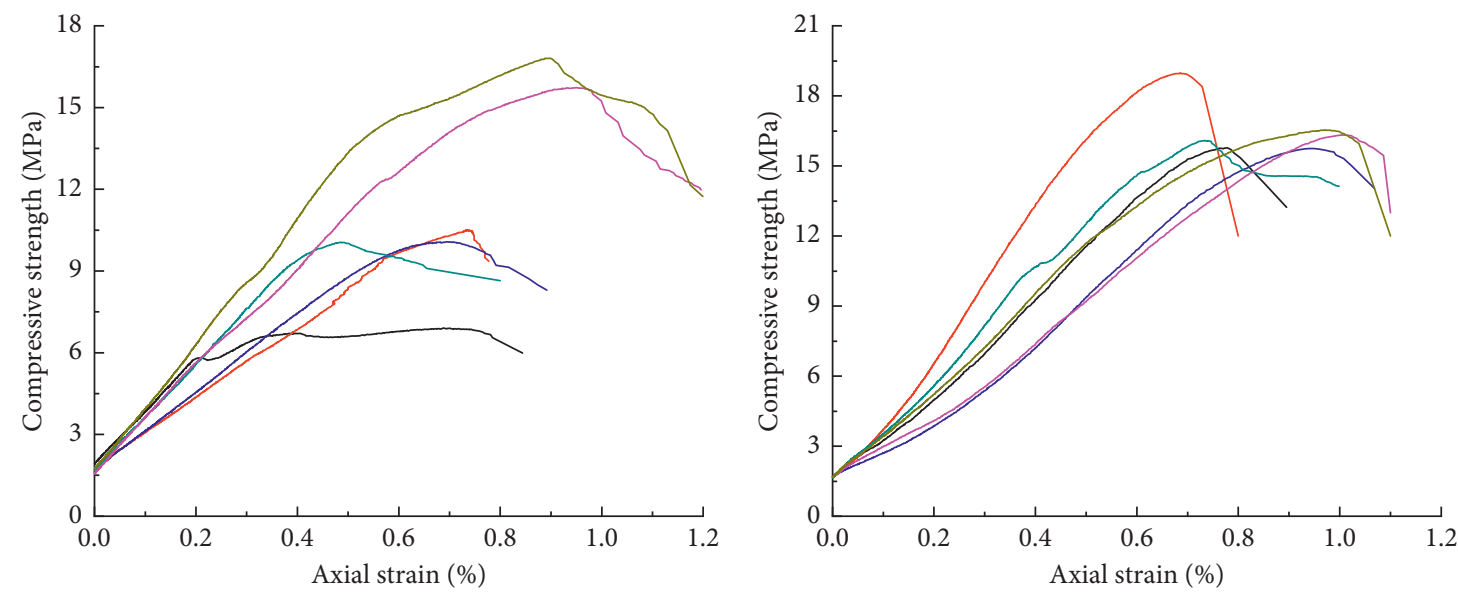

$\begin{array}{ll}-\mathrm{A} 1-1 & -\mathrm{B} 1-2 \\ -\mathrm{A} 1-2 & -\mathrm{C} 1-1 \\ -\mathrm{B} 1-1 & -\mathrm{C} 1-2\end{array}$

A2-1
- A2-2
- B2-1

- B2-2

(a)

FIGURE 5: Continued. 


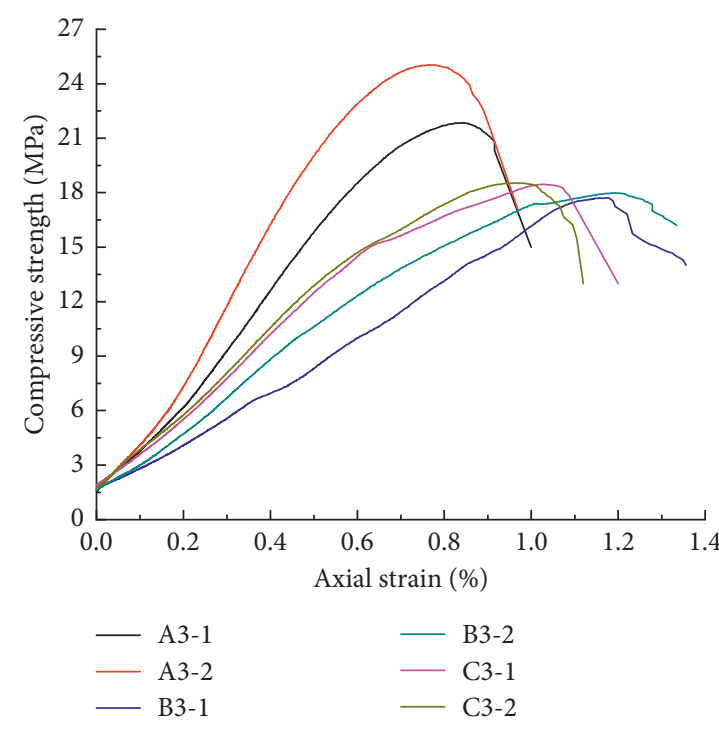

(c)

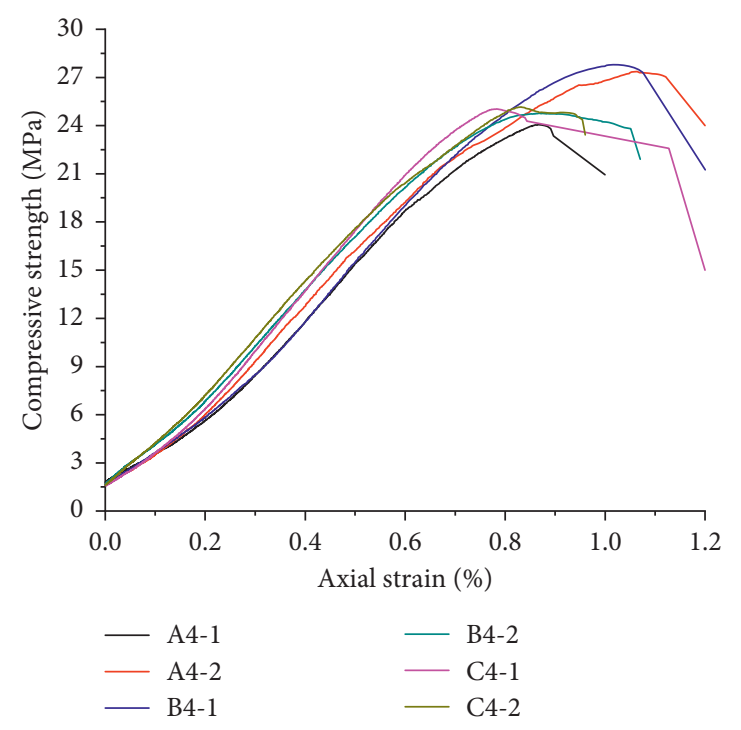

(d)

Figure 5: Single-axial compression stress-strain curve of samples. (a) 7-d stress-strain curve. (b) 14-d stress-strain curve. (c) 21-d stressstrain curve. (d) 28-d stress-strain curve.

TABLE 1: Data of colloid cement without uniaxial compressive strength.

\begin{tabular}{|c|c|c|c|c|}
\hline Age & Number & Strength $(\mathrm{MPa})$ & Longitudinal strain (\%) & Elastic modulus (GPa) \\
\hline \multirow{6}{*}{7} & A1-1 & 6.9071 & 0.6877 & - \\
\hline & A1-2 & 10.5041 & 0.7356 & 1.1866 \\
\hline & B1-1 & 10.0710 & 0.6942 & 1.3766 \\
\hline & B1-2 & 10.0554 & 0.4566 & 1.7840 \\
\hline & $\mathrm{C} 1-1$ & 15.7320 & 0.9510 & 2.0016 \\
\hline & $\mathrm{C} 1-2$ & 16.8128 & 0.8879 & 2.5621 \\
\hline \multirow{6}{*}{14} & A2-1 & 15.7783 & 0.7469 & 2.1862 \\
\hline & A2-2 & 18.9849 & 0.6857 & 3.0946 \\
\hline & B2-1 & 15.7581 & 0.9371 & 2.0306 \\
\hline & B2-2 & 16.0919 & 0.7338 & 2.3040 \\
\hline & $\mathrm{C} 2-1$ & 16.3267 & 1.0040 & 2.2067 \\
\hline & $\mathrm{C} 2-2$ & 16.5436 & 0.9705 & 2.1510 \\
\hline \multirow{6}{*}{21} & A3-1 & 21.8546 & 0.8446 & 2.9703 \\
\hline & A3-2 & 25.0356 & 0.7630 & 3.3304 \\
\hline & B3-1 & 17.7148 & 1.1740 & 2.2601 \\
\hline & B3-2 & 17.9877 & 1.1931 & 2.2901 \\
\hline & C3-1 & 18.4645 & 1.0217 & 2.3318 \\
\hline & $\mathrm{C} 3-2$ & 18.5407 & 0.9700 & 2.3780 \\
\hline \multirow{6}{*}{28} & A4-1 & 24.0530 & 0.8660 & 3.2201 \\
\hline & A4-2 & 27.3693 & 1.0640 & 3.1979 \\
\hline & B4-1 & 27.7923 & 1.0242 & 3.3211 \\
\hline & B4-2 & 24.7682 & 0.8689 & 3.1243 \\
\hline & C4-1 & 25.0289 & 0.7826 & 3.3112 \\
\hline & C4-2 & 25.1592 & 0.8320 & 3.0455 \\
\hline
\end{tabular}

room temperature produces calcium silicate hydrate $(\mathrm{C}-\mathrm{S}-\mathrm{H}$ gel) and $\mathrm{Ca}(\mathrm{OH})_{2}$ :

$$
3 \mathrm{CaOgSiO}_{2}+\mathrm{nH}_{2} \mathrm{O}=\mathrm{xCaSiO}_{2} \mathrm{gyH}_{2} \mathrm{O}+(3-\mathrm{x}) \mathrm{Ca}(\mathrm{OH})_{2}
$$

The effect of the hydration at this stage is related to the water content. As observed, the strength of class A and class $\mathrm{B}$ increases similarly within $14 \mathrm{~d}$. However, with the progress of hydration and water evaporation, the growth of class $\mathrm{B}$ samples slows down after $14 \mathrm{~d}$, which is like that of class C.

At the $21 \mathrm{~d}$, the hydration of the cement paste sample enters the second stage, during which the hydration of dicalcium silicate may be depicted as

$2 \mathrm{CaO} \cdot \mathrm{SiO}_{2}+\mathrm{nH}_{2} \mathrm{O}=\mathrm{xCaO} \cdot \mathrm{SiO}_{2} \cdot \mathrm{yH}_{2} \mathrm{O}+(2-\mathrm{x}) \mathrm{Ca}(\mathrm{OH})_{2}$ 


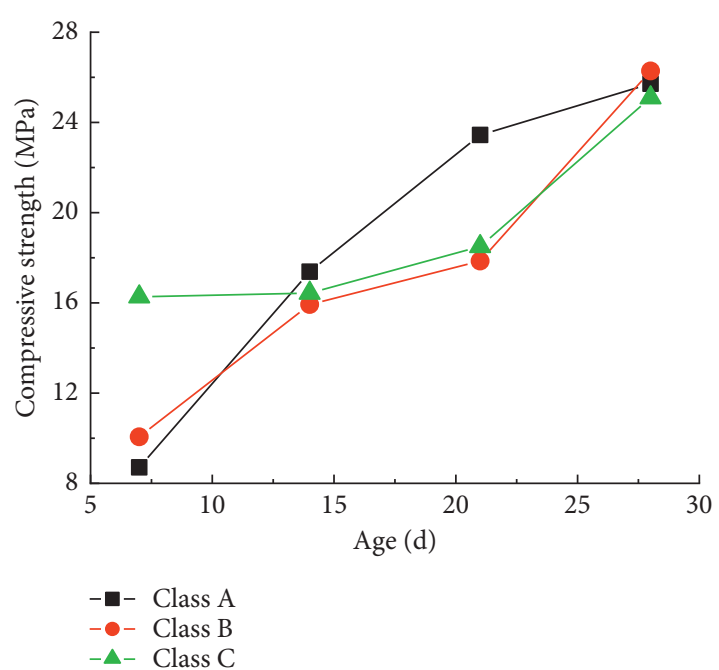

FIgURE 6: The curve of age-compressive strength.

In this stage, the hydration reaction slows down and the crystal particles are relatively large; thus, the growth in the strength of cement paste samples of class A tends to be stable. In the meantime, due to the decline in the hydration reaction and the increase of particles in the samples, the colloid components play a role, causing the crystalline particles to tightly bond and thus the strength of class B and class $\mathrm{C}$ samples increases rapidly. However, due to the decrease in water content of the samples in class $C$ and the lack of crystalline particles formed by the hydration, their growth is no significant than the samples of class B.

\subsubsection{Axial Strain and Elastic Modulus of Colloid Cement} Paste. As shown in Figure 7, as the age increases, the cement paste samples of class A gradually hardens, its axial strain curve gradually increases, and the increase rate was $0.64 \%$, $12.22 \%$, and $20.05 \%$, respectively, compared with the previous age, indicating that the cement paste gradually loses its elasticity and transforms to plasticity as the hydration reaction progresses during the curing period.

On the other hand, the axial strain curves of cement paste samples of class B and C show a turning point after $21 \mathrm{~d}$ age, and the curve of class $B$ samples shows an increasing trend like class A samples, fully indicating that hydration develops plasticity in the sample, while the class $\mathrm{C}$ curve is not obvious due to its low water content. Combining the strength growth law of the colloid cement paste, the binding effect of the colloid component dominates after $21 \mathrm{~d}$, making class $\mathrm{B}$ and class $\mathrm{C}$ samples viscoelastic, and the decrease in axial strain is $1.91 \%$ and $16.34 \%$ compared with the samples of class $\mathrm{A}$ at the age of $28 \mathrm{~d}$, respectively.

As for the elastic modulus of the colloid cement paste, the near straight-line section of the stress-strain curve is selected for calculation and the elastic modulus curve of the samples is drawn (Figure 8). In addition, no calculation is performed due to the large fluctuations in the A1-1 stress-strain curve.

As observed, the elastic modulus curve of the colloid cement paste samples has a trend like the compressive

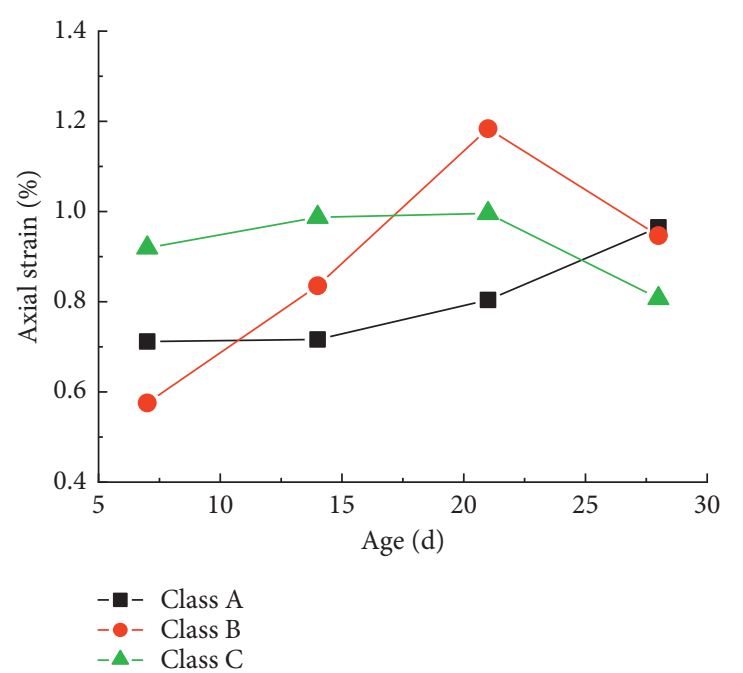

Figure 7: Axial strain curve of colloid cement paste samples.

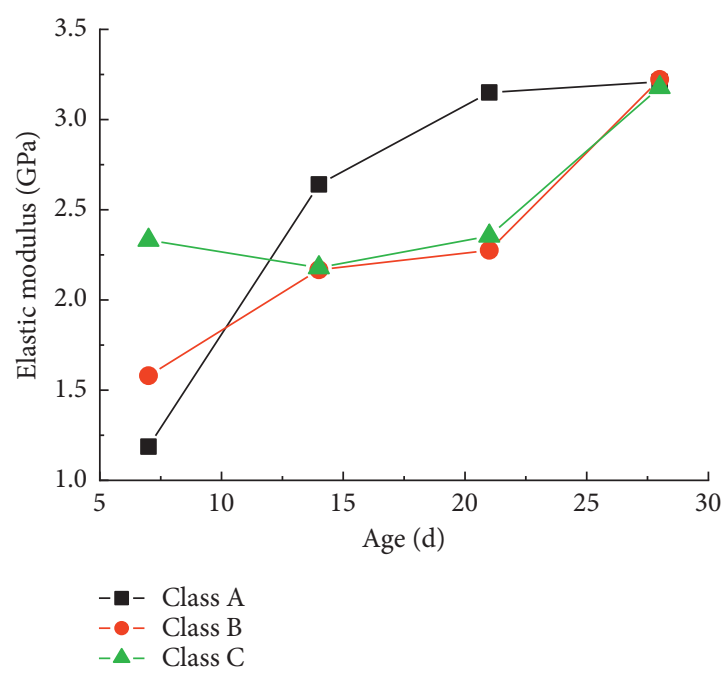

Figure 8: Elastic modulus curve of colloid cement paste samples.

strength curve. With the increase in age, the elastic modulus of cement paste samples shows an overall increasing trend. The elastic modulus curve of cement paste samples of class A tends to be stable from $21 \mathrm{~d}$ to $28 \mathrm{~d}$, indicating that the ability of cement paste to resist deformation reaches its peak; that is, it is difficult to increase the stiffness of the material.

\section{Reinforcement and Compression of Broken Gangues}

3.1. Sample Preparation. The same colloid cement slurry is used for the preparation of reinforcing cement paste samples. During the process of filling the mold of each sample, ten pieces of gangue are placed evenly layer by layer. Each gangue is screened to ensure that its particle size is comparable and the total mass of gangue is strictly controlled to be $122.9 \mathrm{~g}$.

According to the proportion of colloid components, the reinforcing cement paste samples are divided into three 
classes, namely, D, E, and F (the ratio of cement slurry of D and $\mathrm{A}$ is the same, and so on). The colloid reinforcing cement paste samples are divided into four groups, resulting in a total of 12 pieces (Figure 9).

After renumbering the 2 samples with small difference in integrity in each group, uniaxial compressive strength for reinforcing cement paste samples was carried out using the same parameters and steps as the colloid cement paste sample single-axial compression test of the colloid cement paste samples.

\subsection{Compressive Characteristics of Reinforcing Cement Paste.} The single-axial compression test stress-strain curves of the reinforcing cement pastes are shown in Figure 10, and the single-axial compression test data of the samples are displayed in Table 2.

Compared with the compressive stress-strain curve of colloidal cement paste samples, less differences exist in the performance of the reinforced samples at each age, which is due to the addition of broken gangues, reducing the amount of cement slurry and the impact of hydration. Meanwhile, in the stress-strain curve of all ages, the compressive strength of class E samples has an obvious performance that is always greater than the other two classes of samples.

\subsubsection{Compressive Strength Curve of Reinforcing Cement} Paste. As shown in Figure 11, the compressive strength of the reinforcing cement paste samples increases with age after adding broken gangues, while the increasing trends of the three curves are not identical. Among them, the compressive strength of class E cement paste samples increased significantly. In the meantime, as the cement composition varies, the strength of class D, E, and F samples after the end of the curing period is significantly reduced compared to the A, B, and $C$ colloid cement paste samples and decreased by $40.14 \%, 19.54 \%$, and $45.87 \%$, respectively.

The curve transition of the $21 \mathrm{~d}$ age in Figure 6 and the compressive strength at the $7 \mathrm{~d}$ age in Figure 11 fully indicate that the bonding of crystalline particles and broken gangues can enhance the overall strength rather than increase the colloid component content. As shown in Figure 11, the cement slurry mainly undergoes hydration in the early age to enhance its own compressive strength while unbonding with the broken gangues; thus, it is easy to separate and detach them when pressed. In the meantime, by comparing the class $\mathrm{D}$ and $\mathrm{E}$ curves, it can be inferred that part of the moisture is absorbed by gangues after the cement slurry is wrapped with broken gangue, thus affecting the hardening process of cement. Moreover, the colloid component can play the role of water locking to a certain extent, and the compressive strength of class E samples increased by $37.40 \%$ compared with that of class $\mathrm{D}$ samples after the curing period.

Comparing the compressive strength of the class $\mathrm{E}$ samples with the that of other two class at all ages (Figure 12), they increased by $35.10 \%, 55.36 \%, 44.89 \%, 37.39 \%$ and $28.46 \%, 35.19 \%, 58.28 \%, 55.68 \%$, respectively. As observed, the binding effect of the colloid components dominates during the $14 \mathrm{~d}$ age period. The strength of the sample is reflected in the binding ability of the colloid cement slurry to the gangue, and as the cement slurry hydration proceeds, the strength of cement paste also increases. The strength is reflected as the dual role of bonding and hardening.

\subsubsection{Axial Strain and Elastic Modulus Reinforcing Cement} Paste. The axial strain curves of three reinforcing cement paste samples are shown in Figure 13, and comparing with Figure 7, similar trends are found in the curves of the samples from three different classes. However, due to the decrease in cement content, the amplitude of the change in the curves is significantly reduced while the class $\mathrm{E}$ curve also turns in the $21 \mathrm{~d}$ to $28 \mathrm{~d}$ age, indicating that the colloid component endows the reinforcing cement paste sample with viscoelasticity.

Comparing class E samples with the other two kinds of samples (Figure 14), the increase rates of axial strains are $12.57 \%, 14.55 \%, 25.38 \%, 15.33 \%$ and $13.58 \%, 16.83 \%$, $27.77 \%, 32.50 \%$, respectively, significantly lower than the compressive strength of the samples. In the meantime, there is a big turning point at the age of $21 \mathrm{~d}$, which is attributed to the effect of hydration of the cement slurry on the one hand, and on the other hand, it is also verified that the binding cement crystal particles of the colloid component not only increase the strength but also increase the viscoelasticity.

The nearly straight section of the stress-strain curve was selected to calculate the elastic modulus of the reinforcing cement paste samples (Figure 15). The elastic modulus curve of the reinforcing cement paste samples is like that of the compressive strength curve. As the age increases, the elastic modulus of the cement paste sample shows a continuous increasing trend. Different from Figure 7, due to the addition of broken gangues, the colloid component fully exerts the binding effect and plays a dominant role in the early performance of cement paste samples and strengthens broken gangues. The second stage of hydration has a remarkable effect when compared with the first stage.

\section{Results of Orthogonal Tests}

4.1. Design and Results of Orthogonal Tests. An orthogonal test table is designed to compare the effect of the colloid component content and gangue content on the compressive strength and elastic modulus of the cement slurry. Two factors of the colloid component content and gangue content are set, and the colloid component content is divided into three levels $(0 \%, 23.33 \%$, and $33.33 \%)$ while the gangue content is considered for two levels (0\% and 33.33\%) (Table 3), generating the orthogonal test table (Table 4). The experimental data are substituted into the orthogonal test table.

According to the test results of compressive strength and elastic modulus of colloid cement paste samples and reinforcing cement paste samples of various ages, the differentials of orthogonal tests at different ages were obtained (Table 5). 

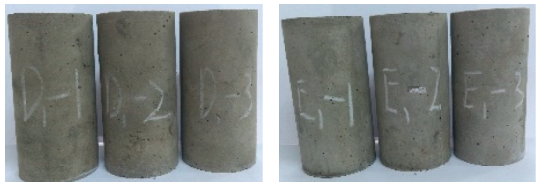

(a)
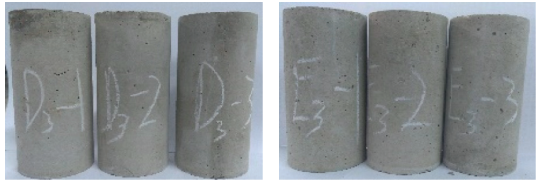

(c)
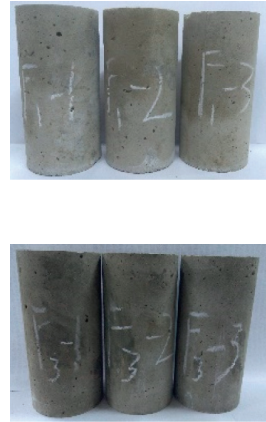
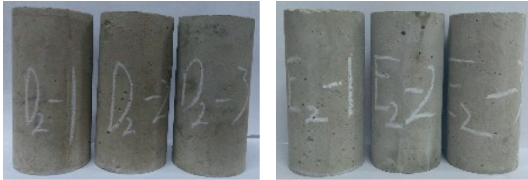

(b)
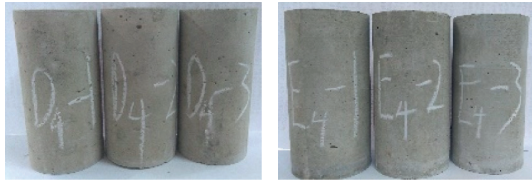

(d)

Figure 9: Reinforcing cement paste sample. (a) $7 \mathrm{~d}$ age sample. (b) $14 \mathrm{~d}$ age sample. (c) $21 \mathrm{~d}$ age sample. (d) $28 \mathrm{~d}$ age sample.
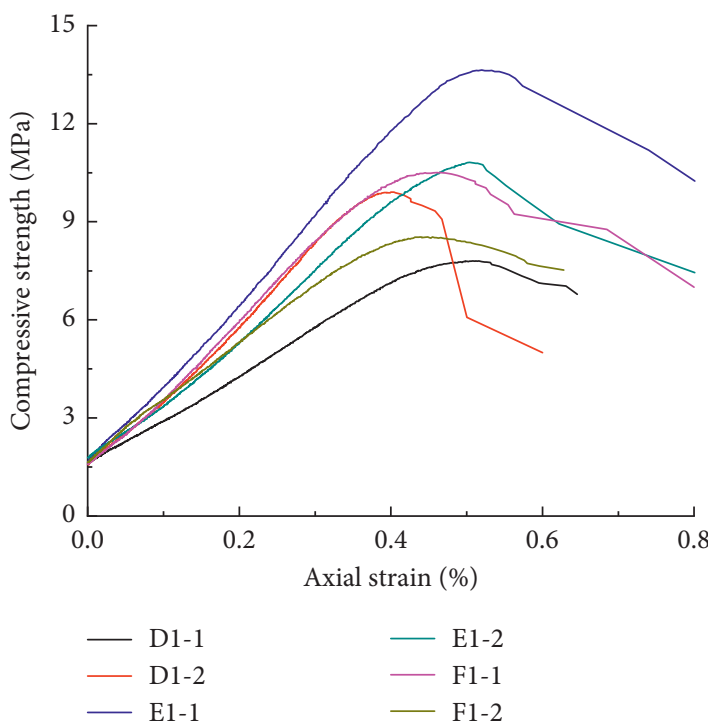

- E1-2

- F1-1

- F1-2

(a)

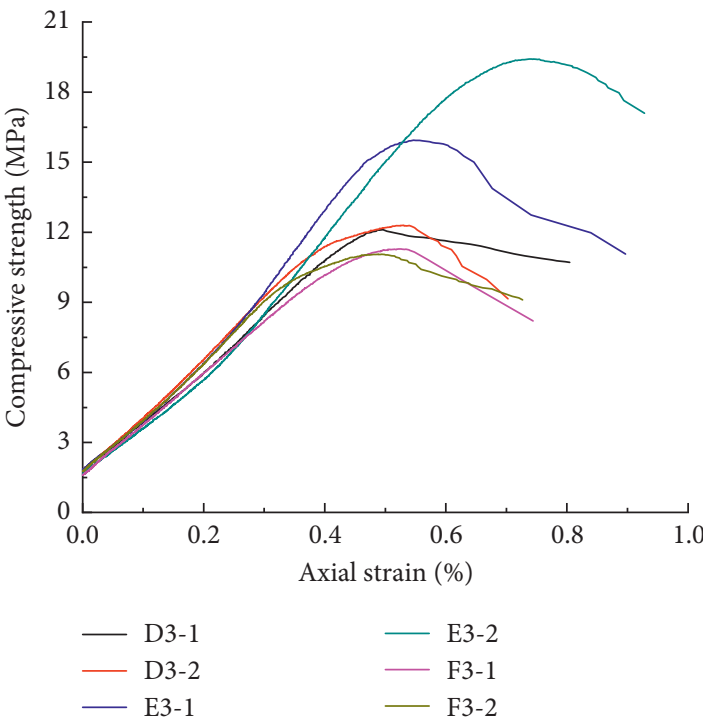

(c)
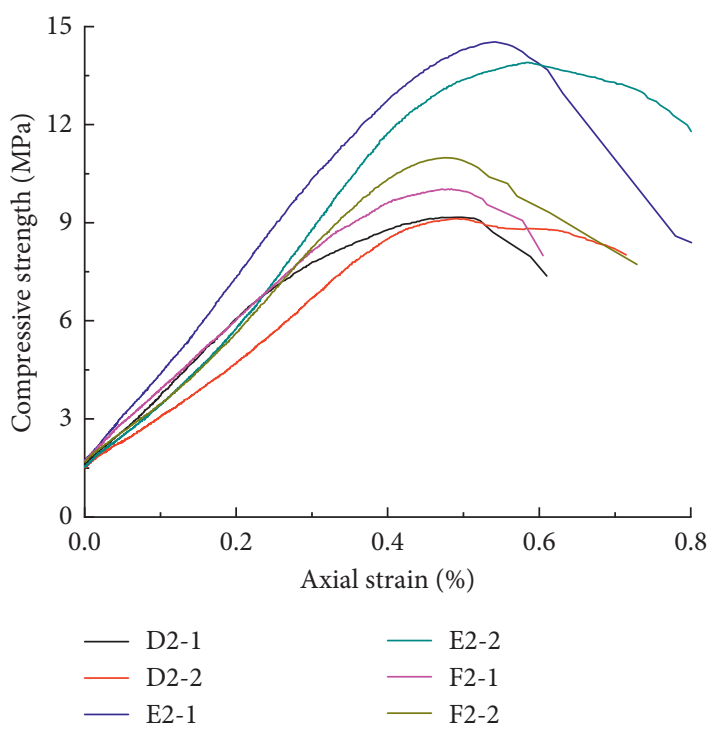

(b)

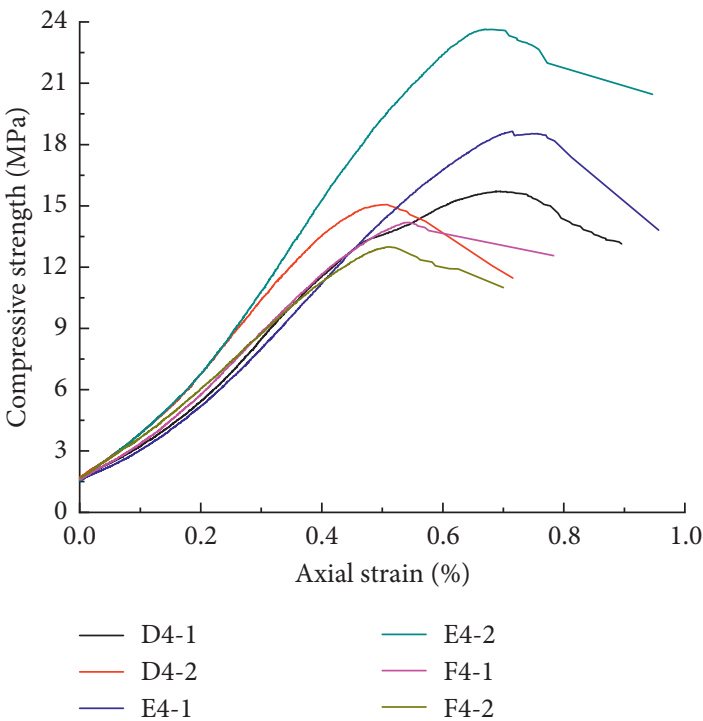

(d)

Figure 10: Single-axial compression stress-strain curve of samples. (a) 7-d stress-strain curve. (b) 14-d stress-strain curve. (c) 21-d stressstrain curve. (d) 28-d stress-strain curve. 
TABLE 2: Uniaxial compressive strength data of reinforcing cement pastes.

\begin{tabular}{|c|c|c|c|c|}
\hline Age (d) & Number & Strength (Mpa) & Longitudinal strain (\%) & Elastic modulus (GPa) \\
\hline \multirow{6}{*}{7} & D1-1 & 7.8025 & 0.5080 & 1.4626 \\
\hline & D1-2 & 9.9049 & 0.4000 & 2.5284 \\
\hline & E1-1 & 13.6379 & 0.5200 & 2.5221 \\
\hline & E1-2 & 10.8159 & 0.5022 & 2.1749 \\
\hline & F1-1 & 10.5042 & 0.4613 & 2.3524 \\
\hline & F1-2 & 8.5322 & 0.4387 & 1.6881 \\
\hline \multirow{6}{*}{14} & D2-1 & 9.1734 & 0.4951 & 2.2623 \\
\hline & D2-2 & 9.1218 & 0.4865 & 1.9652 \\
\hline & E2-1 & 14.5271 & 0.5420 & 2.7108 \\
\hline & $\mathrm{E} 2-2$ & 13.8964 & 0.5824 & 2.7477 \\
\hline & F2-1 & 10.0374 & 0.4840 & 2.1076 \\
\hline & $\mathrm{F} 2-2$ & 10.9881 & 0.4785 & 2.5469 \\
\hline \multirow{6}{*}{21} & D3-1 & 12.1067 & 0.4962 & 2.4531 \\
\hline & D3-2 & 12.2997 & 0.5336 & 2.6467 \\
\hline & E3-1 & 15.9401 & 0.5464 & 3.4712 \\
\hline & E3-2 & 19.4213 & 0.7446 & 3.2349 \\
\hline & F3-1 & 11.2812 & 0.5220 & 2.2047 \\
\hline & F3-2 & 11.0595 & 0.4884 & 2.6645 \\
\hline \multirow{6}{*}{28} & D4-1 & 15.7156 & 0.6953 & 3.1652 \\
\hline & D4-2 & 15.0642 & 0.5069 & 3.4697 \\
\hline & $\mathrm{E} 4-1$ & 18.6444 & 0.7153 & 3.1075 \\
\hline & $\mathrm{E} 4-2$ & 23.6454 & 0.6713 & 4.0035 \\
\hline & F4-1 & 14.1851 & 0.5394 & 2.9847 \\
\hline & F4-2 & 12.9801 & 0.5071 & 2.6289 \\
\hline
\end{tabular}

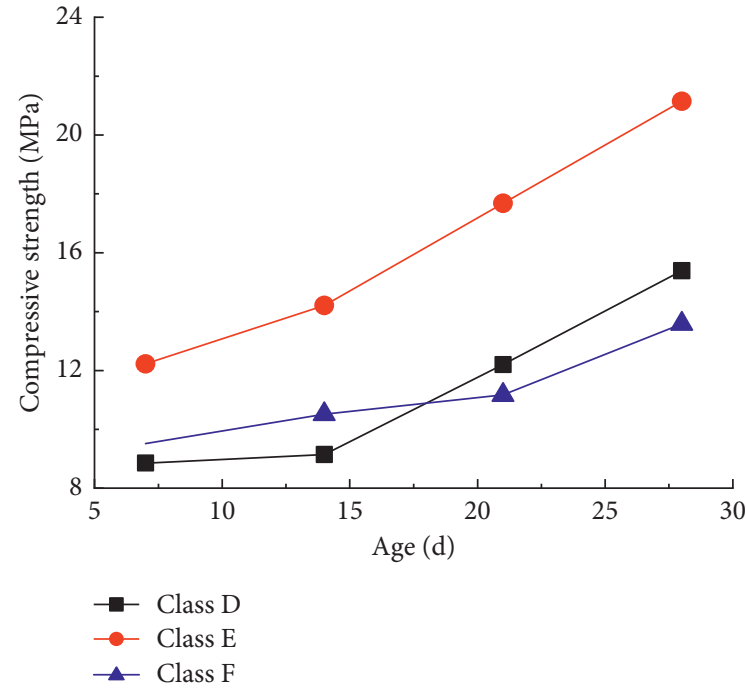

FIgURE 11: Compressive strength curve.

4.2. Differentials of Orthogonal Tests. The differentials of orthogonal tests demonstrated that the main factor affecting the elastic modulus of the cement paste samples at each age is the colloid component content, which fully indicates that the addition of the colloid component effectively increases the viscoelasticity of the cement paste samples. The main influencing factors of compressive strength vary slightly with age, and, overall, the gangue content has a greater impact on the compressive strength of cement paste samples (Figure 16).

Comparing the optimal group of cement paste samples at different ages, the optimal choice of colloid component

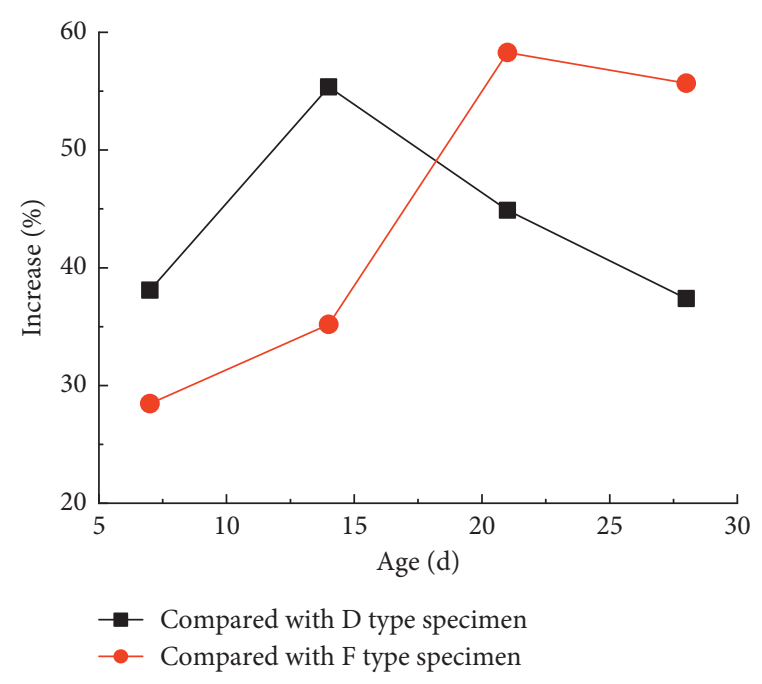

Figure 12: Trend of compressive strength increasing curve.

content gradually decreases with age and then increases instantaneously after the curing period, which is related to the internal hydration of the samples.

At the age of $7 \mathrm{~d}$, hydration is still weak, and the colloid component dominates. Then, the adhesive is applied to increase the strength of the samples. As the hydration increases, the demand for water also increases. The strength of samples with more water content increases significantly, while those with least content of colloid components is optimal. After the age of $21 \mathrm{~d}$, the cement paste sample enters the slow second stage of hydration, and the colloid component greatly increases the strength by bonding the crystal particles produced by hydration. Therefore, the colloid 


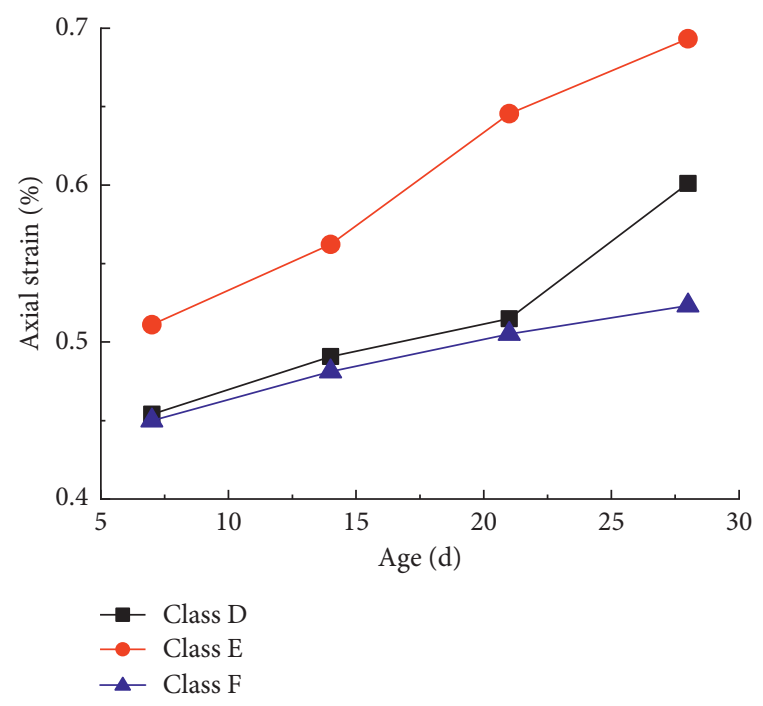

Figure 13: Axial strain curve of reinforcing cement paste.

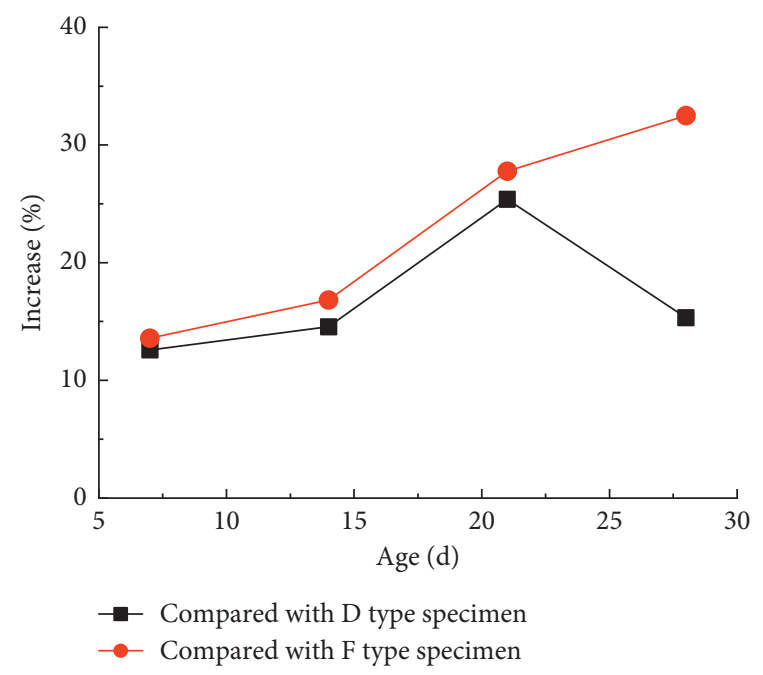

FIGURE 14: Increasing curve of axial strain.

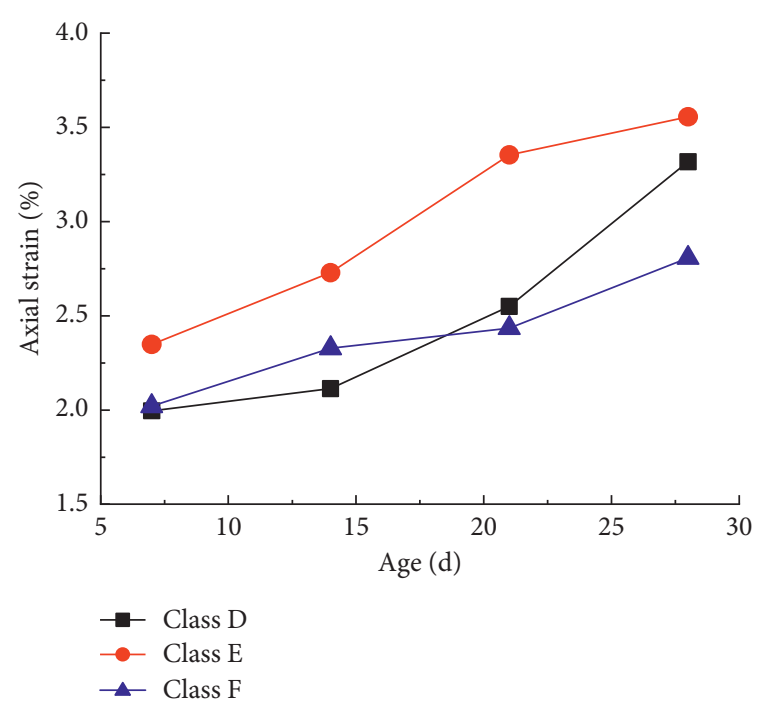

Figure 15: Elastic modulus curve of reinforcing cement paste.
TABLE 3: Factors and levels of orthogonal tests.

\begin{tabular}{lcc}
\hline $\begin{array}{l}\text { Factors } \\
\text { Levels }\end{array}$ & Colloid component content (\%) & Gangue content (\%) \\
\hline 1 & 0.00 & 0 \\
2 & 23.33 & 33.33 \\
3 & 33.33 & \\
\hline
\end{tabular}

component content of $23.33 \%$ is the optimal choice after comprehensive consideration. Meanwhile, the differentials show that the lower the gangue content, the higher the strength of cement paste samples, which indicates that the slurry formulation with lower aggregate content should be selected as far as possible in the downhole grouting and shotcrete work.

\section{Failure Mode of Cement Paste Samples}

5.1. Analysis of Failure Modes. The failure mode of cement paste with $28 \mathrm{~d}$ age was selected for analysis (Figures 17 and 18 ); as observed, the failure mode of the reinforcing cement paste samples with gangue was more complicated than that of colloid cement paste samples.

The main control surface of various cement paste samples is obviously damaged, showing penetrating splitting failure. However, the surface morphology of the cement paste samples containing colloid components remains more complete when they are destroyed, and their peeling is relatively slight compared to the cement paste samples, indicating that the colloid components have a good bonding effect.

5.2. Classification of Instability Modes. According to the failure mode of the cement paste, the instability of the cement paste sample can be divided into dispersed loadbearing instability mode and cumulative load-bearing instability mode.

(1) In the dispersed load-bearing instability mode, tiny cracks appear at the weak points of the crystal particles inside the cement paste samples during the process of resistance to deformation. During the gradual increase in load bearing, the cracks at various points continue to evolve throughout and link with each other to form new cracks. While the penetrating failure of the main control surface occurs, the continuous development of small cracks also causes the peeling of the sample surface (Figure 19(a)), which is suitable for the failure of cement paste samples with no or low colloid component content.

(2) In the cumulative load-bearing instability mode, the colloid component makes the bonding between the crystal particles or between the crystal particles and broken gangues closer. In the process of resisting deformation, the pressure continues to accumulate and release on the weak surface, generating fewer fine cracks and forming a single penetrating channel, resulting in the instability and failure of the samples in the process of releasing the stress. This is the 
TABLE 4: Orthogonal tests.

\begin{tabular}{lcr}
\hline Sample number & Factor A (colloid component content) (\%) & Factor B (gangue content) (\%) \\
\hline 1 & $2(23.33)$ & $2(33.33)$ \\
2 & $2(23.33)$ & $1(0.00)$ \\
3 & $1(0.00)$ & $2(33.33)$ \\
4 & $3(33.33)$ & $2(33.33)$ \\
5 & $3(33.33)$ & $1(0.00)$ \\
6 & $1(0.00)$ & $1(0.00)$ \\
\hline
\end{tabular}

Table 5: Differentials of orthogonal tests.

\begin{tabular}{|c|c|c|c|c|c|c|c|}
\hline \multirow[t]{2}{*}{ Items } & \multirow[t]{2}{*}{ Analysis index } & \multicolumn{2}{|c|}{$\begin{array}{l}\text { Results of } \\
\text { compressive } \\
\text { strength }\end{array}$} & \multicolumn{2}{|c|}{$\begin{array}{l}\text { Results of } \\
\text { elastic } \\
\text { modulus }\end{array}$} & \multirow[t]{2}{*}{ Conclusion of compressive strength } & \multirow[t]{2}{*}{ Conclusion of elastic modulus } \\
\hline & & A & $\mathrm{B}$ & A & $\mathrm{B}$ & & \\
\hline \multirow{4}{*}{$7 \mathrm{~d}$ age } & $\mathrm{K}_{1}$ & 8.78 & 11.68 & 1.591 & 1.683 & Priority & Priority \\
\hline & $\mathrm{K}_{2}$ & 11.145 & 10.2 & 1.964 & 2.121 & $\mathrm{~A}>\mathrm{B}$ & $\mathrm{A}>\mathrm{B}$ \\
\hline & $\mathrm{K}_{3}$ & 12.895 & - & 2.151 & - & \multicolumn{2}{|c|}{ Optimal group of compressive strength } \\
\hline & $\mathrm{R}$ & 4.115 & 1.48 & 0.56 & 0.438 & \multicolumn{2}{|c|}{$\mathrm{A}_{3} \mathrm{~B}_{1}$} \\
\hline \multirow{4}{*}{$14 \mathrm{~d}$ age } & $\mathrm{K}_{1}$ & 13.265 & 16.581 & 2.377 & 2.329 & Priority & Priority \\
\hline & $\mathrm{K}_{2}$ & 15.068 & 11.291 & 2.448 & 2.39 & $\mathrm{~B}>\mathrm{A}$ & $\mathrm{A}>\mathrm{B}$ \\
\hline & $\mathrm{K}_{3}$ & 13.474 & - & 2.253 & - & \multicolumn{2}{|c|}{ Optimal group of compressive strength } \\
\hline & $\mathrm{R}$ & 1.803 & 5.29 & 0.195 & 0.061 & \multicolumn{2}{|c|}{$\mathrm{A}_{2} \mathrm{~B}_{1}$} \\
\hline \multirow{4}{*}{$21 \mathrm{~d}$ age } & $\mathrm{K}_{1}$ & 17.824 & 19.933 & 2.85 & 2.593 & Priority & Priority \\
\hline & $\mathrm{K}_{2}$ & 17.766 & 13.685 & 2.814 & 2.779 & $\mathrm{~B}>\mathrm{A}$ & $A>B$ \\
\hline & $\mathrm{K}_{3}$ & 14.837 & - & 2.395 & - & \multicolumn{2}{|c|}{ Optimal group of compressive strength } \\
\hline & $\mathrm{R}$ & 2.987 & 6.248 & 0.455 & 0.186 & $\mathrm{~A}_{1} \mathrm{~B}_{1}$ & \\
\hline \multirow{4}{*}{$28 \mathrm{~d}$ age } & $\mathrm{K}_{1}$ & 20.551 & 25.695 & 3.263 & 3.203 & Priority & Priority \\
\hline & $\mathrm{K}_{2}$ & 23.713 & 16.706 & 3.389 & 3.227 & $\mathrm{~B}>\mathrm{A}$ & $\mathrm{A}>\mathrm{B}$ \\
\hline & $\mathrm{K}_{3}$ & 19.338 & - & 2.993 & - & \multicolumn{2}{|c|}{ Optimal group of compressive strength } \\
\hline & $\mathrm{R}$ & 4.375 & 8.989 & 0.396 & 0.024 & $\mathrm{~A}_{2} \mathrm{~B}_{1}$ & \\
\hline
\end{tabular}

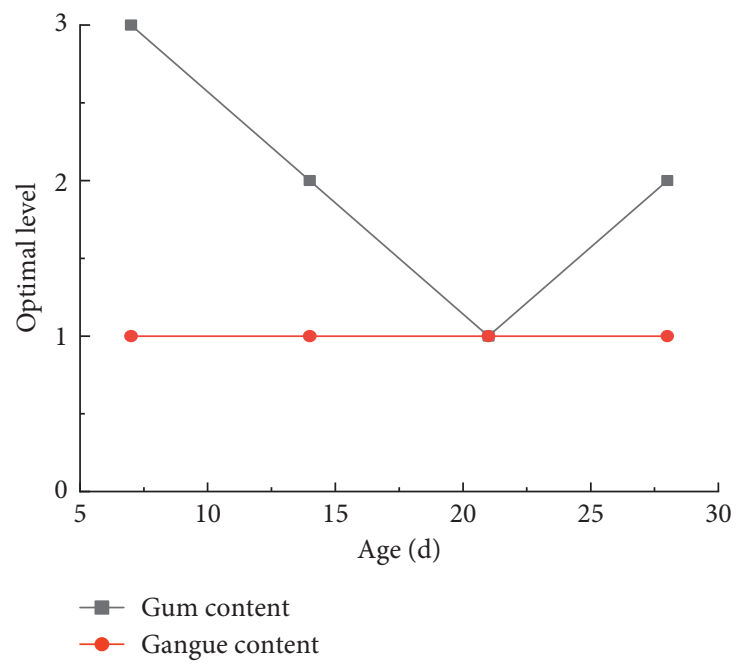

Figure 16: Optimal levels. 


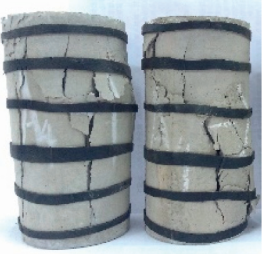

(a)

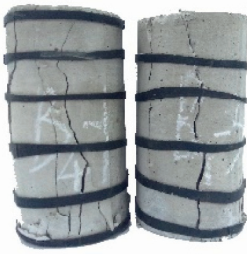

(b)

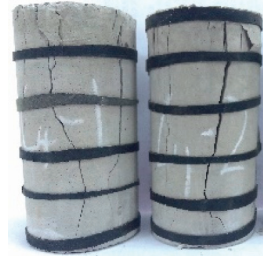

(c)

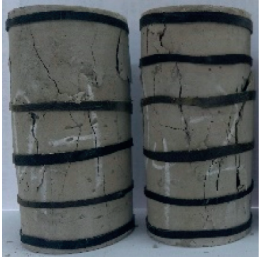

(d)

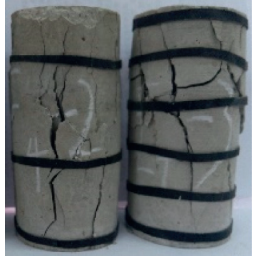

(e)

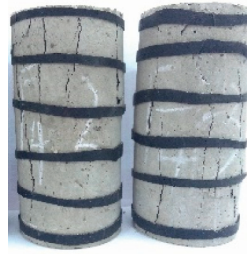

(f)

Figure 17: Failure mode of cement paste. (a) Group A. (b) Group B. (c) Group C. (d) Group D. (e) Group E. (f) Group F.

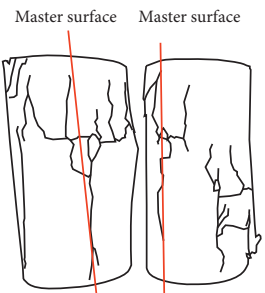

(a)

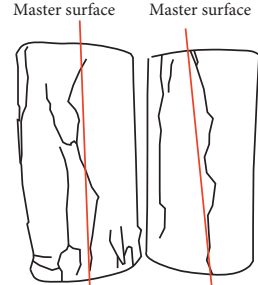

(b)

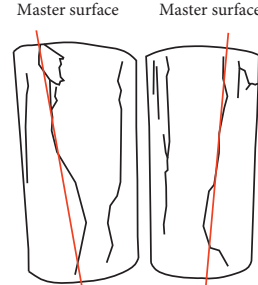

(c)

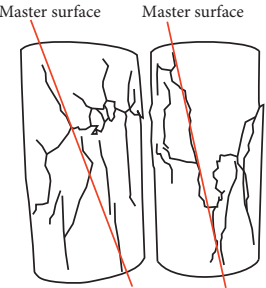

(d)

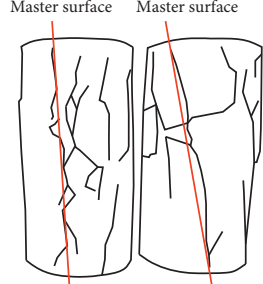

(e)

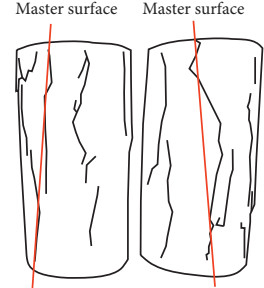

(f)

Figure 18: Destruction sketch of cement paste. (a) Group A. (b) Group B. (c) Group C. (d) Group D. (e) Group E. (f) Group F.
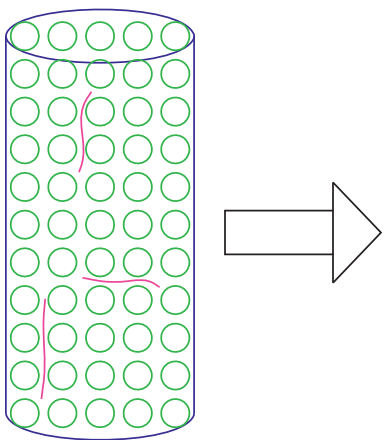

(a)
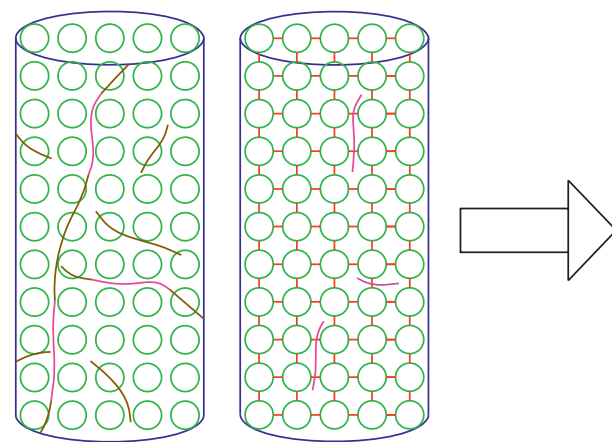

(b)

FIGURE 19: Instability mode of cement paste sample. (a) Dispersed load-bearing instability mode. (b) Cumulative load-bearing instability mode.

mechanism of instability of cement paste samples with a high proportion of colloid components.

\section{Conclusions}

The results obtained made it possible to draw the following conclusions.

(1) In this study, the hardening process of the colloid cement paste samples during the curing period was elucidated and the full stress-strain curve during each age was obtained, indicating that the colloid component has a significant strengthening effect on the early strength of cement paste.

(2) As the age increases, the axial strain and elastic modulus of the colloid cement paste samples increase overall, and the colloid component renders the samples with a certain viscoelasticity when resisting deformation.

(3) The stress-strain curves of reinforcing cement paste samples at each age were obtained, showing that the strength of the samples decreases after the addition of broken gangues. Meanwhile, it is found that the strength of class E samples increases significantly during each age.

(4) As the age increased, the axial strain and elastic modulus of the reinforcing cement paste samples also increased, and from the comparison, the increase in the class $\mathrm{E}$ samples is obvious, and the addition of the colloid component leads to the formation of cement paste with viscoelasticity.

(5) The cement paste samples showed penetrating splitting failure, the colloid component effectively 
controlled the surface peeling of the cement paste samples, and the failure mode of samples after adding the gangue was relatively complex.

(6) The instability mode of cement paste samples is divided into dispersed load-bearing instability and cumulative load-bearing instability, and the proportion of colloid components affects the failure modes of cement paste samples.

\section{Data Availability}

The data used for conducting classifications are available from the corresponding author authors upon request.

\section{Conflicts of Interest}

The authors declare that they have no conflicts of interest.

\section{Acknowledgments}

The authors are grateful for the financial support provided by the Chinese Excellent Young Talents Support Program Project in Universities (gxyq-ZD2019025) and China Shanxi Province Announced Bidding Project (no. 20191101016).

\section{References}

[1] W. J. Yu and K. Li, Deformation Mechanism and Control Technology of Surrounding Rock in the Deep-Buried LargeSpan Chamber, GEOFLUIDS, London, UK, 2020.

[2] W. J. Yu and F. F. Liu, "Stability of close chambers surrounding rock in deep and comprehensive control technology," Advances in Civil Engineering, vol. 2018, 2018.

[3] G. Z. Dai, K. X. Yin, and X. Shi, "Experimental study of cement grouting material of increasing primary strength for anchor engineering," Journal of Mining \& Safety Engineering, vol. 1, pp. 83-87, 2006.

[4] M. F. Jiang and X. J. Lv, "Research and application progresses of concrete early strength agent," Bulletin of the Chinese Ceramic Society, vol. 33, no. 10, pp. 2527-2533, 2014.

[5] G. Marchetti, E. F. Rahhal, and R. V. Fatima, "Effects of packing density and water film thickness on fresh and hardened properties of ternary cement pastes," Advances In Cement Research, vol. 32, no. 10, pp. 444-455, 2020.

[6] T. Gonen and S. Yazicioglu, "The effect of curing conditions on permeation of self-compacting lightweight concrete with basaltic pumice aggregate," Arabian Journal for Science and Engineering, vol. 43, no. 10, pp. 5157-5164, 2018.

[7] H. G. Li, "Experiment on mixing ratio of grouting material for treatment of coal mine goaf," Journal of Highway and Transportation Research and Development, vol. 28, no. 8, pp. 35-40, 2011.

[8] T. Meng, K. L. Qian, X. Q. Qian, and S. L. Zhan, "Effect of the nano- $\mathrm{CaCO}_{3}$ on hydrated properties and interface of cement paste," Rare Metal Materials and Engineering, vol. 37, no. S2, pp. 667-669, 2008.

[9] J. J. Roa, S. Simison, J. Grasso et al., "Cyclic contact fatigue of cemented carbides under dry and wet conditions: correlation between microstructure, damage and electrochemical behaviour," International Journal of Refractory Metals \& Hard Materials, vol. 92, 2020.
[10] C. N. Fernandes, R. L. S. Ferreira, R. D. S. Bernardo, F. Avelino, and A. A. Bertini, "Using $\mathrm{TiO}_{2}$ nanoparticles as a $\mathrm{SO}_{2}$ catalyst in cement mortars," Construction And Building Materials, vol. 257, 2020.

[11] V. V. Gedam, P. K. Labhasetwar, and C. J. Engelsen, “CCR characterization and valorization as mineral additives during cement production in India," International Journal of Coal Preparation and Utilization, vol. 40, no. 8, pp. 524-538, 2020.

[12] M. Ozturk, M. Karaaslan, O. Akgol, and U. K. Sevim, "Mechanical and electromagnetic performance of cement based composites containing different replacement levels of ground granulated blast furnace slag, fly ash, silica fume and rice husk ash," Cement And Concrete Research, vol. 136, 2020.

[13] B. Z. E. L. abidine, B. Salah, B. Noureddine, Z. F. Ralida, and T. Djamel, "Effect of coal additives on the physical and chemical properties of the Portland cement," International Journal of Coal Preparation and Utilization, vol. 39, no. 2, pp. 55-64, 2019.

[14] J. Li, S. Q. Zhang, Q. Wang et al., "Feasibility of using fly ashslag-based binder for mine backfilling and its associated leaching risks," Journal of Hazardous Materials, vol. 400, pp. 123-191, 2020.

[15] W. Liu, Y. Q. Li, S. F. Lin et al., "Changes in chemical phases and microscopic characteristics of fly ash blended cement pastes in different $\mathrm{CO}_{2}$ concentrations," Construction And Building Materials, vol. 257, 2020.

[16] Y. F. Zheng, G. Fargas, O. Lavigne, E. Roitero, and L. Llanes, "Corrosion-induced changes on Hertzian contact damage in cemented carbides," International Journal of Refractory Metals \& Hard Materials, vol. 92, 2020.

[17] H. Mohammadhosseini, N. H. A. S. Lim, M. M. Tahir et al., "Effects of waste ceramic as cement and fine aggregate on durability performance of sustainable mortar," Arabian Journal For Science And Engineering, vol. 45, no. 5, pp. 3622-3634, 2020.

[18] I. Ahmad, K. A. Khan, and T. Ahmad, "Influence of chloroprene rubber latex on set times and early hydration of cement," Arabian Journal For Science And Engineering, vol. 45, no. 10, pp. 7975-7986, 2020.

[19] Y. Li, Q. J. Ding, and S. G. Hu, "Utilization of limestone as mineral admixture in cement and concrete," Journal of Wuhan University of Technology(Materials Science), vol. 3, pp. 35-37, 2007.

[20] B. G. Han, Z. Lin, and J. P. Ou, "Piezoresistivity of cementbased materials with nickel powder," Rare Metal Materials and Engineering, vol. 38, no. S1, pp. 265-270, 2009.

[21] T. Meng, K. L. Qian, X. Q. Qian, and S. L. Zhan, "Effect of composite nano-addition on mechanics strength and microstructure of cement paste," Rare Metal Materials and Engineering, vol. 37, no. S2, pp. 631-633, 2008.

[22] C. Zhang, H. Liu, S. Li et al., "Experimental study on the expansion of a new cement-based borehole sealing material using different additives and varied water-cement ratios," Arabian Journal For Science And Engineering, vol. 44, no. 10, pp. 8717-8725, 2019.

[23] Y. Ma, X. X. Li, J. S. Qian, and X. D. Shen, "Effect of protogenetic alkali sulfates on the hydration and hardening of cement with different tricalcium aluminate content," Construction And Building Materials, vol. 256, 2020.

[24] W. Yu, F. Zhang, S. Yao, and B. Pan, "Bearing capacity and dynamic reliability of surrounding rock and supporting structure in deep roadway," Geotechnical and Geological Engineering, vol. 38, no. 6, pp. 5885-5895, 2020. 
[25] B. B. Sun, H. Wu, W. M. Song, Z. Li, and J. Yu, "Hydration, microstructure and autogenous shrinkage behaviors of cement mortars by addition of superabsorbent polymers," Frontiers of Structural and Civil Engineering, vol. 2020, 2020.

[26] S. Arshad, M. B. Sharif, M. Irfan-ul-Hassan, M. Khan, and J.-L. Zhang, "Efficiency of supplementary cementitious materials and natural fiber on mechanical performance of concrete," Arabian Journal for Science And Engineering, vol. 45, no. 10, pp. 8577-8589, 2020.

[27] B. G. Han and J. P. Ou, "The humidity sensing property of cements with added carbon," New Carbon Materials, vol. 23, no. 4, pp. 382-384, 2008.

[28] K. Z. Li, C. Wang, H. J. Li, F. Luo, and D. S. Hou, "Reflectivity of carbon-fiber-reinforced cement-based composites against electromagnetic waves," Rare Metal Materials and Engineering, vol. 36, no. 10, pp. 1702-1708, 2007.

[29] W. J. Yu, B. Pan, F. Zhang, S. F. Yao, and F. F. Liu, "Deformation characteristics and determination of optimum supporting time of alteration rock mass in deep mine," KSCE Journal of Civil Engineering, vol. 23, no. 11, pp. 4924-4932, 2019.

[30] Z. F. Li, S. C. Li, and R. T. Liu, "Development of the grouting material for reinforcing water-rich broken rock masses and its application," Rock and Soil Mechanics, vol. 37, no. 7, pp. 1937-1946, 2016.

[31] L.-J. Hou, Z.-Y. Luan, D. Chen, and S.-L. Xu, "Experimental study of the shear properties of reinforced ultra-high toughness cementitious composite beams," Journal of Zhejiang University-SCIENCE A, vol. 16, no. 4, pp. 251-264, 2015.

[32] C. F. Revelo and H. A. Colorado, "A green composite material of calcium phosphate cement matrix with additions of car tire waste particles," International Journal of Applied Ceramic Technology, vol. 2020, 2020.

[33] D. Wu, R. Zhao, W. Hou, and S. Wang, "A coupled thermomechanical damage modeling application of cemented coal gangue-fly ash backfill under uniaxial compression," Arabian Journal For Science And Engineering, vol. 45, no. 5, pp. 3469-3478, 2020. 